\title{
Antigenic and genotypic characterization of Echinococcus granulosus larval isolates from Egypt
}

Original Article

\section{Manar EI Tonsy, Ahmed Fikry, Heba Aminou, Omima Hassanin, Hala Abdelhafiz}

Medical Parasitology Department, Faculty of Medicine, Ain-Shams University, Cairo, Egypt

\begin{abstract}
Background: Cystic echinococcosis (CE), caused by the larval stage of Echinococcus granulosus, is a global zoonotic infection of economic importance constituting a threat to public health in many countries. E. granulosus exists as a complex of different strains that have an impact on the epidemiology and control of CE, the most important of which are G1 and G6 strains. In Egypt, some studies confirm the predominance of G1 strain while others demonstrated the involvement of camel G6 strain in causing human infection.

Objective: To study the diagnostic potential of purified antigenic yields of hydatid cyst fluid (HCF) from Egyptian CE patients and DNA corresponding to different recorded genotypes, in addition to the characterization of E. granulosus genotype in human and animal isolates in Egypt.

Subjects and Methods: Crude HCF antigens from 30 patients were extracted and fractionated by sodium dodecyl sulfatepolyacrylamide gel electrophoresis (SDS-PAGE) and probed by enzyme immunoelectrotransfer blot (EITB) against sera from CE patients and 50 controls. HCF from human and animal isolates was obtained and prepared for DNA extraction and the amplification of the predominant genotype bands at $254 \mathrm{bp}$.

Results: PCR applied to HCF protoscolices of human and camels showed a typical $254 \mathrm{bp}$ band of $12 \mathrm{~S}$ fragment of mitochondrial gene belonging to G6 genotype (camel strain). SDS-PAGE fractionation of crude HCF antigen gave a protein profile composed of 11 bands. Immunoblotting assay showed that anti-E. granulosus IgG of patients' sera recognized 9 antigenic bands, varying in molecular weight from 12-110 kDa. The 48 and $12 \mathrm{kDa}$ bands detected in all patients' sera disappeared after treatment.

Conclusion: This study confirmed the predominance of G6 genotype (camel strain) of cystic echinococcosis in Egypt. PCR using the amplification primers of G6 genotype is a promising tool in the diagnosis of CE using either patients' HCF or sera. The use of EITB in the diagnosis and post-treatment follow up of G6 genotype CE patients proved of high sensitivity and specificity. The recognition of 48 and $12 \mathrm{kDa}$ antigenic proteins in $100 \%$ of CE cases' sera and their disappearance after treatment marks their usefulness in diagnosis and follow up of CE cases.
\end{abstract}

Key Words: Echinococcosis, EITB, hydatid cyst fluid, PCR, SDS-PAGE.

Received: 23 January 2017, Accepted: 5 December, 2017.

Corresponding Author: Heba Aminou, Tel. : +20-10-0155-0924, E-mail: hebaaminou74@hotmail.com.

ISSN: 1687-7942, Vol. 11, No. 1, April 2018.

\section{INTRODUCTION}

Cystic echinococcosis (CE), caused by the larval stage of E. granulosus, is an economically important global zoonotic infection that constitutes a threat to public health in many countries ${ }^{[1]}$. It occurs in almost all communities of the underdeveloped and developed worlds ${ }^{[2]}$. Humans are accidental intermediate hosts infected by ingestion of food or water contaminated with dog feces containing the infective eggs ${ }^{[3]}$. In Egypt, it was reported that CE has become endemic which adds to the burden on Egyptian livers affected by viral hepatitis and schistosomiasis ${ }^{[4]}$. $\mathrm{CE}$ in the liver was found to represent $3 \%$ of the causes of acute and chronic liver diseases among 200 patients in Assiut ${ }^{[5]}$. Hence, CE has a considerable economic and social impact, because it has numerous complications leading to important disabilities and even death ${ }^{[6]}$.The liver is the most common site of echinococcal cysts (65\%), followed by the lungs $(25 \%)^{[7]}$. The initial phase of primary infection is usually asymptomatic especially cysts of less than $5 \mathrm{~cm}$ that may remain asymptomatic for years or permanently in up to $60 \%$ of patients ${ }^{[8]}$. However, cysts may cause jaundice, pancreatitis and biliary cirrhosis ${ }^{[9]}$. Chest pain, cough, dyspnea, and hemoptysis due to rupture of the pulmonary capillaries may occur in case of lung cyst affection $^{[10]}$.

E. granulosus exists as a complex of different strains that differ in a wide variety of criteria and therefore have an impact on the epidemiology and control of $\mathrm{CE}^{[11]}$ Although some reports denoted that the most important strain associated with human CE appeared to be sheep G1 strain ${ }^{[12]}$, the molecular characterization of human and animal isolates demonstrated the involvement of the camel G6 strain in causing human infection ${ }^{[13-15]}$. In Egypt, G6 involvement has been shown by a number of 
studies $^{[13,16,17]}$. Hydatid cyst fluid (HCF) is antigenically rich, consisting of a complex mixture of glycol- and lipoproteins, carbohydrates and salts, and is therefore considered the main antigenic source for immunodiagnosis of human $\mathrm{CE}^{[18]}$. On the other hand, in the chronic phase of $\mathrm{CE}$, there is frequent occurrence of elevated antibody levels, particularly $\operatorname{IgG}, \operatorname{IgM}$, and $\operatorname{IgE}$ with predominance of IgG1 and IgG4 subclasses ${ }^{[20]}$. However, the sensitivity of serological tests is affected by many factors including site, integrity of hydatid cysts and quality of antigen used $^{[21]}$. Early diagnosis of CE by serology may provide opportunities for early treatment, more effective chemotherapy as well as follow-up after treatment ${ }^{[22]}$. The aim of the present work is: i) to characterize E. granulosus genotype in human and animal isolates in Egypt; ii) to separate human HCF antigenic componants; iii) to assess the diagnostic accuracy of indirect enzyme linked EITB using the different antigenic fractions; iv) to study the diagnostic potential of a PCR assay on patients' sera using the amplification primer of the recovered genotype.

\section{SUBJECTS AND METHODS}

This descriptive analytical study for nucleic acids and antigenic evaluations included 90 subjects (30 CE patients, $10 \mathrm{CE}$ treated cases, 50 controls) of both sexes; and animal isolates from camels and sheep.

Human cases: Patients ages ranged from 10-60 years. They were classified into two main groups: Group I included 40 CE patients, subdivided into Gp IA: 20 cases of hepatic CE; Gp IB: 6 cases of pulmonary CE; Gp IC: 4 cases of CE with multiple organs affection; and Gp ID: 10 cases of CE after medical and/or surgical treatment. Group II included control sera from 30 patients with diseases other than $\mathrm{CE}$ and 20 normal individuals, subdivided into Gp IIA: 15 patients with other parasitic infections as schistosomiasis (7), fascioliasis (6), taeniasis (1) and amoebic liver abscess (1); Gp IIB: 15 patients with other mass occupying lesions as hepatocellular carcinoma (8), simple idiopathic liver cyst (2) and bronchogenic carcinoma (5); Gp IIC: 20 normal controls were apparently healthy individuals with no history of parasitic infections, negative urine and stool examination and negative indirect hemagglutination test (IHAT) for hydatid disease.

All human subjects in the studied groups were from Cairo and Giza and they were selected according to complete medical history, physical examination, laboratory investigations, IHAT, and imaging techniques (chest Xray, abdominal U/S and/or CT scan). A $5 \mathrm{ml}$ blood sample was collected from all 90 patients in a sterile tube; the serum was separated and stored at $-20^{\circ} \mathrm{C}$ to be used later. Blood samples were taken from patients during operation, or immediately after confirming the infection by puncture aspiration injection re-aspiration (PAIR) technique. Human hydatid cyst fluid from CE patients was collected by therapeutic PAIR procedure or from surgically removed cysts, in sterile centrifuge tubes.

Animal isolates: Cysts from animal hosts (camel and sheep) were obtained from Cairo abattoirs. Only fertile cysts were used in the study.

Processing of $\mathrm{HCF}$ of human and animal isolates ${ }^{[23]}$ : For detection of G6 or G1 of CE (Operon Biotechnologies, Germany), protoscolices were isolated by centrifugation and prepared for DNA extraction. DNA was extracted using "QIAamp® DNA Mini Kit"(QIAGEN, Germany), which enables DNA extraction from tissue (protoscolices) and fluid samples (serum samples). Before analysis, the concentration of the extracted DNA was determined by spectrophotometer. For the antigenic study crude HCF antigen was prepared from centrifuged supernatants ${ }^{[24]}$, followed by determination of protein concentration, using Bio Rad protein assays method ${ }^{[25]}$.

PCR quality control: PCR is an impressively sensitive procedure; therefore, the following was done to ensure its quality: strict separation between the area used for DNA preparation and extraction (pre-lab) and the one used in the preparation of the reaction mixture of PCR (lab) or in PCR product analysis (gel electrophoresis), with separate equipments in each area; maintenance and calibration of pipettes; thermocyclers were checked regularly to determine that all wells reach desired temperatures; UV radiation at $254 \mathrm{~nm}$ wavelength was used to decontaminate any reagent (except primers and Taq) or equipment; $70 \%$ ethanol and $10 \%$ commercial bleach solutions $(5 \%$ sodium hypochlorite) were used for decontaminating all equipments; use of positive control (reference strain) to ensure absence of PCR inhibitors and negative control (reagents without DNA template) to ensure absence of contaminating DNA, in each PCR run.

EITB by sodium dodecyl-sulphate polyacrylamide gel electrophoresis (SDS-PAGE) ${ }^{[26]}: 25 \mu \mathrm{g}$ of human crude HCF antigen pool was electrophoresed in $12 \%$ polyacrylamide gel under reducing conditions and stained by Coomassie blue stain. Hyperimmune hydatid rat serum was prepared as described by Shariff and Parija ${ }^{[27]}$ and was used as positive control serum, against crude HCF antigen pool. The proteins were electrophoretically transferred into 2- $\mu \mathrm{m}$ nitrocellulose membranes using Bio-Rad Mini-Protean II gel electrophoresis apparatus containing trans-blot cell ${ }^{[28]}$. The blots were used in identification and characterization of antigen by antibody probes, from positive sera and visualized by enzyme-conjugated secondary antibodies ${ }^{[29]}$.

Statistical analysis of results: The data were collected and processed in a personal computer (PC) IBM compatible, and analyzed with the aid of the Statistical Package for Social Science (SPSS) Version 11.0.1 for windows. The 
statistical tests used were Mann-Whitney test, Chi-square test, sensitivity, specificity, positive and negative predictive values, efficacy and accuracy.

Ethical consideration: An informed consent was obtained from all patients before taking the required clinical samples. The study was approved by the Research Ethics Committee, Faculty of Medicine, Ain Shams University.

\section{RESULTS}

Detection of genotype in HCF protoscolices from patients with $\mathrm{CE}$ and camel isolates showed a positive band at $254 \mathrm{bp}$ corresponding to G6 genotype reference strain (camel strain) in 100\% of cases (Figures 1,2). Using G6 genotype amplification primers on sera from patients with CE showed that 27 out of $30 \mathrm{CE}$ cases had positive characteristic bands at $254 \mathrm{bp}$ (Figure 3), while sera of patients six to twelve months after treatment showed no bands (Table1). Sera of the control group showed no bands corresponding to G6 genotype.

SDS-PAGE fractionation of crude $\mathrm{HCF}$ antigen from 30 human $\mathrm{CE}$ cases showed a protein profile composed of

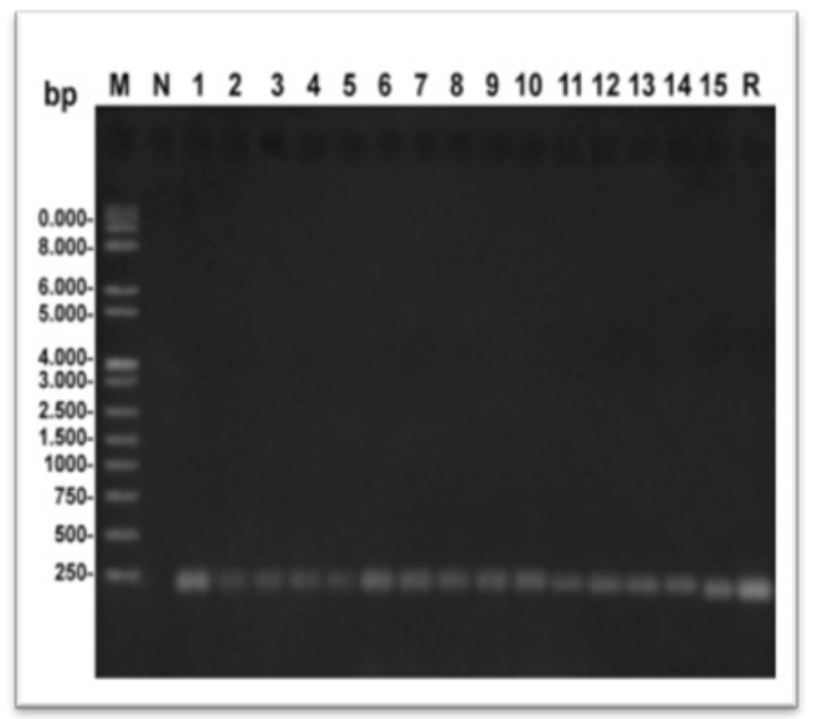

Fiwg. 1. Results of G6 genotype PCR in human isolates showing a typical band at $254 \mathrm{bp}$ on $1.5 \%$ agarose gel electrophoresis stained with ethidium bromide.

Lane M: DNA molecular marker.

Lane N: Negative control of PCR (no template DNA).

Lane 1-10: Positive human isolates (hepatic CE).

Lane 11: Positive human isolate (pulmonary $\mathrm{CE}$ ).

Lane 12-15: Positive human isolate (Multiple organs).

Lane R: Reference strain of G6 genotype (Camel strain)
11 bands: $164,130,110,80,75,48,35,25,20,18$ and $12 \mathrm{kDa}$ (Figure 4). By EITB, the anti E. granulosus IgG recognized 9 antigenic bands, varying in molecular weight from $110 \mathrm{kDa}$ to $12 \mathrm{kDa}(110,80,75,65,56,48,35,25$ and 12). Different EITB bands were produced by sera of CE cases in Gp I-A, B, C, and control groups (Table 2 and Figure 5); and 1 antigenic band was recognized by sera of Gp I- D (Table 3). The validity of EITB using human crude antigen against sera of patients in GpI-A, B, C and control group is shown in table (2). Statistical analysis of the molecular weights bands recognized by the anti $E$. granulosus $\mathrm{IgG}$ of the studied groups sera revealed that the $48-\mathrm{kDa}$ and $12-\mathrm{kDa}$ protein bands reacted in sera of the $30(100 \%)$ patients. None of the sera from control group (Gp П) recognized the $12 \mathrm{kDa}$ band, while only 2 (4\%) schistosomal sera recognized the $48 \mathrm{kDa}$ band, indicating a significant difference $(P<0.01)$. Other antigenic bands of 75,56 and $25 \mathrm{kDa}$ were also detected by the $\mathrm{IgG}$ of CE Gp I-A, B and C with sensitivity of $23.3 \%, 10 \%$ and $33.3 \%$, respectively and $100 \%$ specificity, also indicating a highly significant difference $(P<0.01)$. Moreover, the $35 \mathrm{kDa}$ antigenic protein was recognized by $66.7 \%$ of the $\mathrm{CE}$ sera IgG, but also showed cross reaction of $4 \%$ with 2 schistosomiasis sera from the control group.

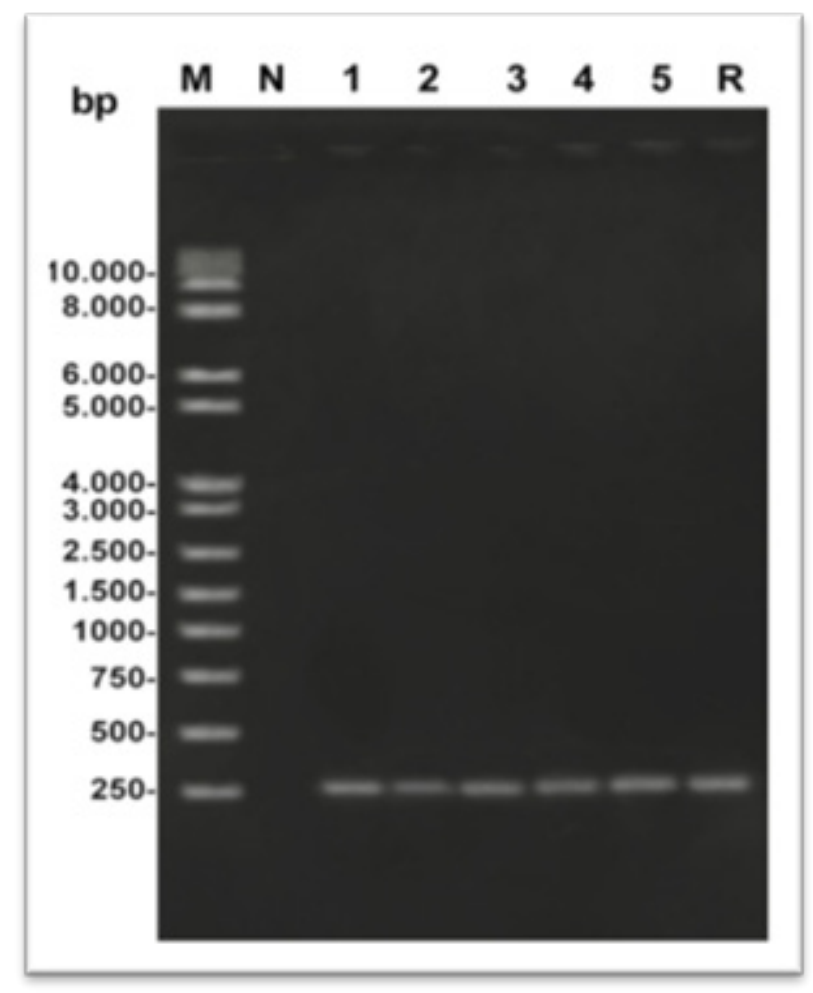

Fig. 2: Results of G6 genotype PCR in camel isolates showing a typical band at 254 bp on $1.5 \%$ agarose gel electrophoresis stained with ethidium bromide.

Lane M: DNA molecular marker.

Lane N: Negative control of PCR (no template DNA).

Lane 1-5: Positive camel isolates.

Lane R: Reference strain of G6 genotype (Camel strain). 


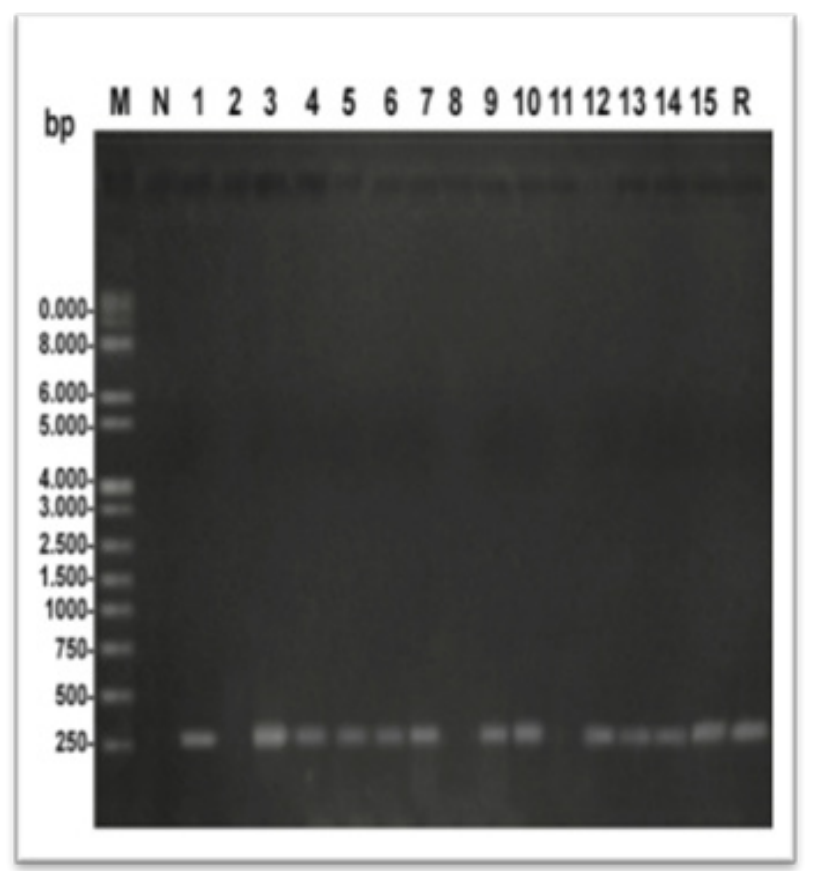

Fig. 3: Results of G6 genotype PCR in the sera of CE patients (Gp I-A, B, C) on 1.5\% agarose gel electrophoresis stained with ethidium bromide.

Lane M: DNA molecular marker.

Lane N: Negative control of PCR (no template DNA).

Lanes: $1,3,4,5,6,7,9,10,12,13,14,15$ positive CE sera at 254 bp. band.

Lanes 2 and 8: Negative Hepatic CE sera at 254 bp. band.

Lane 11: Negative Pulomanry CE sera at $254 \mathrm{bp}$. band.

Lane R: Reference strain of G6 genotype (Camel strain).

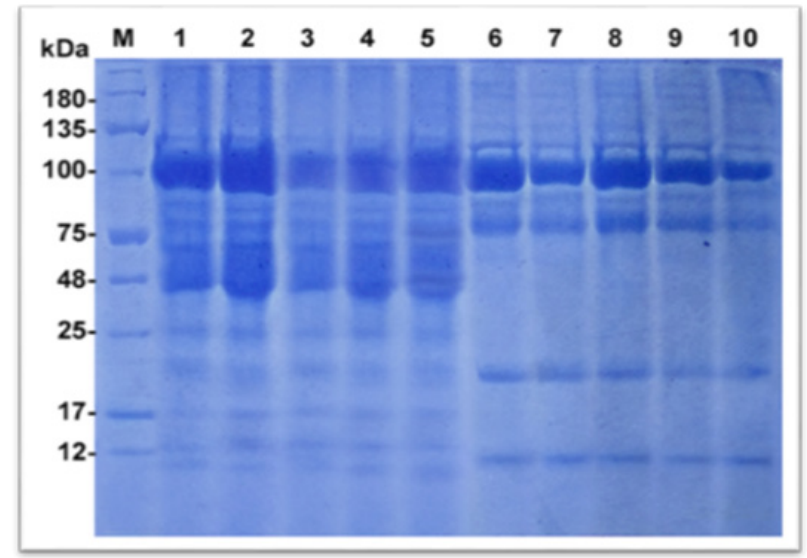

Fig. 4: SDS-PAGE profiles of human crude HCF protein separated on $12 \%$ polyacrylamide gel, stained by Coomassie blue stain.

-Lane M: Broad range molecular weight standard marker.

- Lane 1-5: Hepatic crude HCF antigens.

-Lane 6-10: Pulmonary crude HCF antigens.

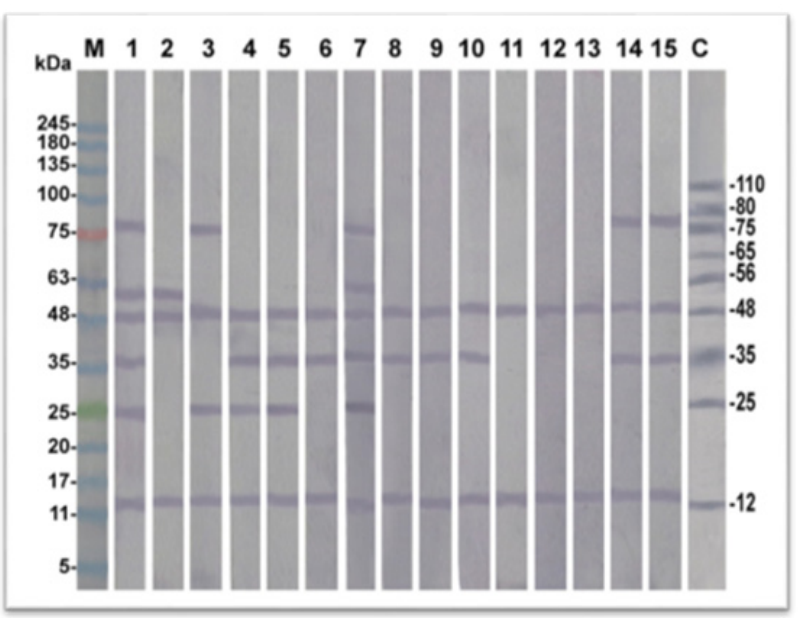

Fig. 5: Immunoblot analysis showing recognition of E. granulosus antigenic bands by specific IgG in sera among CE patients ( $\mathrm{Gp}$ I-A, B, C).

-Strip M: Broad range molecular weight standard.

-Strips 1-8: Sera from Hepatic CE patients.

-Strips 9-13: Sera from Pulmonary CE patients.

-Strips 14 and 15: Sera from multi-organ CE patients.

-Strip C: Positive control (hyperimmune rat serum).

Table 1: Results of PCR for sera of CE patients and control groups using G6 genotype primers.

\begin{tabular}{|c|c|c|c|}
\hline \multirow{2}{*}{ Gp } & \multicolumn{2}{|c|}{ PCR of serum for G6 genotype } & \multirow{2}{*}{ Total N } \\
\hline & + ve N (\%) & -ve N $(/ \%)$ & \\
\hline Gp I-A & $18(90)$ & $2(10 \%)$ & 20 \\
\hline Gp I-B & $5(83.3)$ & $1(16.7 \%)$ & 6 \\
\hline Gp I-C & $4(100)$ & $0(0 \%)$ & 4 \\
\hline Gp I-D & $0(0)$ & $10(100)$ & 10 \\
\hline Gp II-A & $0(0)$ & $15(100 \%)$ & 15 \\
\hline Gp II-B & $0(0)$ & $15(100 \%)$ & 15 \\
\hline Gp II-C & $0(0)$ & $20(100 \%)$ & 20 \\
\hline Total & $27(30 \%)$ & $63(70 \%)$ & 90 \\
\hline
\end{tabular}

N.: number, \%: percentage, +ve: positive, -ve: negative. 
Table 2: Statistical analysis of recognized EITB bands by sera of Gp I (A, B, C) and Gp II (control group using human pool) and its validity.

\begin{tabular}{|c|c|c|c|c|c|c|c|c|}
\hline \multirow{2}{*}{$\begin{array}{l}\text { IB band } \\
(\mathrm{kDa})\end{array}$} & \multicolumn{2}{|c|}{ Group I (cases) } & \multicolumn{2}{|c|}{$\begin{array}{c}\text { Group II (control } \\
\text { group) }\end{array}$} & \multirow{2}{*}{$\begin{array}{l}\text { Statistical } \\
\text { analysis } \\
\text { Chi } \\
\text { Square test }\end{array}$} & \multirow[t]{2}{*}{ P value } & \multirow[t]{2}{*}{$\begin{array}{c}\text { Sensitivity } \\
(\%)\end{array}$} & \multirow[t]{2}{*}{$\begin{array}{c}\text { Specificity } \\
(\%)\end{array}$} \\
\hline & + ve N (\%) & -ve N (\%) & + ve N (\%) & -ve N (\%) & & & & \\
\hline 110 & $0(0)$ & $30(100)$ & $0(0)$ & $50(100)$ & - & - & 0 & 100 \\
\hline 80 & $0(0)$ & $30(100)$ & $0(0)$ & $50(100)$ & - & - & 0 & 100 \\
\hline 75 & $7(23.3)$ & $23(76.7)$ & $0(0)$ & $50(100)$ & 12.78 & $<0.01$ & 23.3 & 100 \\
\hline 65 & $0(0)$ & $30(100)$ & $0(0)$ & $50(100)$ & - & - & 0 & 100 \\
\hline 56 & $3(10)$ & $27(90)$ & $0(0)$ & $50(100)$ & 5.20 & 0.049 & 10 & 100 \\
\hline 48 & $30(100)$ & $0(0)$ & $2(4)$ & $48(96)$ & 72.00 & $<0.01$ & 100 & 96 \\
\hline 35 & $20(66.7)$ & $10(33.3)$ & $2(4)$ & $46(92)$ & 36.93 & $<0.01$ & 66.7 & 96 \\
\hline 25 & $10(33.3)$ & $20(66.7)$ & $0(0)$ & $50(100)$ & 19.05 & $<0.01$ & 33.3 & 100 \\
\hline 12 & $30(100)$ & $0(0)$ & $0(0)$ & $50(100)$ & 80.00 & $<0.01$ & 100 & 100 \\
\hline
\end{tabular}

N.: number, \%: percentage, +ve: positive, -ve: negative.

Table 3: Antigenic bands detected by sera of CE patients after treatment (Gp I- D).

\begin{tabular}{lccc}
\hline \hline $\begin{array}{l}\text { IB band } \\
\text { (kDa) }\end{array}$ & Gp I- D & -ve (N) & Positivity (\%) \\
\hline $\mathbf{1 1 0}$ & + ve (N) & 10 & 0 \\
$\mathbf{8 0}$ & 0 & 10 & 0 \\
$\mathbf{7 5}$ & 0 & 10 & 0 \\
$\mathbf{6 5}$ & 0 & 10 & 0 \\
$\mathbf{5 6}$ & 0 & 10 & 0 \\
$\mathbf{4 8}$ & 0 & 10 & 0 \\
$\mathbf{3 5}$ & 0 & 6 & 0 \\
$\mathbf{2 5}$ & 4 & 10 & 0 \\
$\mathbf{1 2}$ & 0 & 10 & 0 \\
\hline \hline
\end{tabular}

N.: number, \%: percentage, +ve: positive, -ve: negative.

\section{DISCUSSION}

A recent molecular characterization of CE-causing strains in human and animals in Egypt was performed to conclude whether the G6 (camel strain) and/or G1 (sheep strain) are responsible for human CE in Egypt. This PCR system detected a part of the mitochondrial $12 \mathrm{~S}$ ribosomal RNA (rRNA) gene to amplify the fragment of $254 \mathrm{bp}$. In the present work, PCR applied to parasite HCF's protoscolices of human (hepatic, pulmonary and multi-organ CE) and camels isolates, showed that they are all of G6 genotype (camel strain). This is in accordance with other studies from Egypt by Azab et al. ${ }^{[13]}$ who used RAPD-PCR, Abdel Aaty et al. ${ }^{[16]}$ using Hot-Start PCR technique, and Khalifa et al. ${ }^{[17]}$ using nested PCR (nPCR) for the first time in diagnosis of E. granulosus in Egypt. The latter authors revealed absence of variation in amplified DNA in all fertile cysts from camels and humans with high similarity with DNA fingerprinting of E. granulosus G6 positive control indicating the zoonotic association.
In previous studies, from Iran and Kenya where G1 coexists with G6, it was shown that G1 predominated in human cases and G6 appeared to be non-infective to human ${ }^{[23,30]}$. Later on, other molecular studies within the same areas detected the G6 genotype in human samples ${ }^{[1,31]}$, probably due to the introduction of recent accurate molecular and genotyping techniques. In the present work, all the HCF protoscolices of human and camel isolates were screened with G1 strain primers and they showed no band. In another record G7 genotype (pig strain) was detected in two human isolates and one pig isolate in Egypt, while G1 genotype (sheep strain) was detected in one human isolate from Yemen and in no animal isolates. This was the first record of G7 in Egypt and G1 in Yemen ${ }^{[32]}$.

The predominance of the camel strain G6 genotype in the present study was also similar with that from Sudan, where all human, camel and sheep hydatid cysts isolates were of G6 genotype ${ }^{[1,33]}$. In previous reports ${ }^{[14-17]}$ G6 genotype was the predominant genotype in Egypt 
indicating that camels are the main animal reservoir of CE and also explaining the significance of CE patients sera reactivity with camel $\mathrm{HCF}^{[34]}$.

Fine needle aspiration (FNAB) or PAIR which was accepted as a complementary diagnostic and therapeutic tool ${ }^{[8]}$, is the best method to establish the specific diagnosis of the $\mathrm{CE}$, including microscopy of the aspirated hydatid fluid to demonstrate brood capsules and protoscolices. However, it carries the great disadvantage of anaphylactic reaction and development of secondary echinococcosis from leakage of cyst fluid ${ }^{[35]}$; besides the failure of exclusion of sterile hydatid cysts. So detection of parasite nucleic acids in clinical samples other than HCF has become of great importance. The detection of G6 or G1 genotype in sera of human CE infected with these strains was possible according to the theory of DNA passage through hydatid cyst wall mini-fissures to the blood ${ }^{[35-37]}$, which supported the detection of E. granulosus DNA in serum for a definitive diagnosis of CE. In the present study, results of PCR using serum of CE cases (who were all G6 positive with HCF protoscolices in PCR) and G1 and G6 primers showed 90\% sensitivity using G6 genotype amplification primer and none for $\mathrm{G} 1$ amplification primers. This provided a valuable molecular tool for diagnosis of $\mathrm{CE}$ in human serum. However, when compared to HCF examination, the sensitivity of PCR was $90 \%$ in serum, whereas that of the HCF showed $100 \%$. The three negative serum samples $(2$ hepatic and 1 pulmonary cysts) were of CE patients with partly calcified small cysts less than $5 \mathrm{~cm}$ in size. Patients tested six to twelve months after treatment showed no bands, which confirms the sensitivity of PCR for detection of the parasite DNA and its value in management.

In spite of the relatively lower sensitivity of PCR in sera compared to microscopic examination of $\mathrm{HCF}$, as gold standard test, still using serum is easier and safer in sampling than HCF obtained by FNAB during surgery or by PAIR technique. It has been shown that intermediate hosts produce a significant immune response against E. granulosus infection ${ }^{[38]}$ and that in chronic phases of $\mathrm{CE}$, there is frequent occurrence of elevated antibody levels ${ }^{[19]}$. Serological diagnosis plays a key role not only in early detection of $\mathrm{CE}$ infection, but also in long-term monitoring of patients who had underwent surgery or drug treatment ${ }^{[39]}$. To overcome drawbacks of serological tests, standardization of techniques, antigenic preparations, and characterization of new antigens, are required to improve the performance of CE immunodiagnosis ${ }^{[40]}$. The EITB assay for the diagnosis of $\mathrm{CE}$ has been reported to be more specific than ELISA and Dot-ELISA. It also combines the high sensitivity and specificity of immunoenzyme tests with the high resolution of specific proteins in SDS$\mathrm{PAGE}^{[35]}$. In the present study, E. granulosus human HCF antigens of the proven G6 genotype isolates were used to detect IgG in sera of studied groups by EITB in order to characterize new antigenic epitopes.
Under reducing conditions the $12 \mathrm{kDa}$ band which is believed to be a subunit of HCF AgB, showed 100\% sensitivity (including the three cases that were negative by PCR) and specificity with no cross reaction of any tested control sera. This is in agreement with the study of Haniloo et $a l .{ }^{[41]}$ in which the blotted $8 / 12 \mathrm{kDa}$ of $\mathrm{AgB}$ showed $70 \%$ and $100 \%$ sensitivity and specificity, respectively. This high sensitivity and specificity of $12 \mathrm{kDa}$ band in the present study signifies it as a good marker for diagnosis of CE patients. Moreover, the $12 \mathrm{kDa}$ band wasn't detected in the present study by the E. granulosus IgG in sera of the patients 6-12 month after treatment (Gp I- D), signifying it as a good marker for post treatment follow up. The 48 $\mathrm{kDa}$ band showed $100 \%$ sensitivity but it was also detected by 2 schistosomal sera making it less reliable in diagnosis than the $12 \mathrm{kDa}$ band. The $35 \mathrm{kDa}$ band persisted in 4 patients, making it less reliable. This antigenic band may be related to E. granulosus Ag5, which is a high molecularweight glycoprotein complex $(>500 \mathrm{kDa})$ containing the 57 and $67 \mathrm{kDa}$ bands ${ }^{[22]}$. In SDS polyacrylamide gels, under reducing conditions $67 \mathrm{kDa}$ is dissociated into 22 and 38 $\mathrm{kDa}$ subunits ${ }^{[43]}$.

In conclusion, the present study confirmed that the main genotype responsible for E. granulosus human infection in Egypt is G6, the camel strain, and that PCR is very sensitive and specific in the diagnosis of CE using either patients HCF or sera. The use of EITB in diagnosis and post-treatment follow up of CE patients showed high sensitivity in the identification of potent antigens in HCF. The 48 and $12 \mathrm{kDa}$ antigenic proteins were detected in $100 \%$ of CE patients sera and disappeared 6-12 months after treatment signifying their sensitivity for the use in diagnosis and post treatment follow up. No new antigens were identified.

Author contribution: All authors contributed in study design, collection of materials, methodology, writing the manuscript and revising it.

Acknowledgment: The authors would like to thank the medical staff in the Abdominal Ultrasonographic Unit of Tropical Medicine Department, Kasr El-Aini Hospital; the Diagnostic and Research Laboratory of Parasitic Diseases in the Department of Medical Parasitology, Faculty of Medicine, Ain Shams University; the Departments of Cardiothoracic Surgery, Tropical Medicine and Chest Medicine (pulmonary diseases and tuberculosis), Faculty of Medicine, Ain Shams University.

\section{REFERENCES}

1. Dinkel A, Njoroge EM, Zimmermann A, Walz M, Zeyhle E, Elmahdi IE et al. A PCR system for detection of species and genotypes of the Echinococcus granulosus-complex, with reference to the epidemiological situation in Eastern Africa. Int $\mathrm{J}$ Parasitol 2004; 34(5): 645-653. 
2. Craig PS, Larrieu E. Control of cystic echinococcosis/ hydatidosis: 1863-2002. Adv Parasitol 2006; 61: 443 508.

3. Naseri-Moghddam S, Abrishami A, Taefi A, Malekzadeh R. Percutaneous needle aspiration injection and re-aspiration with or without benzimidazole coverage for uncomplicated hepatic hydatid cysts. Cochrane Database Syst Rev 2011, 1: CD003623.

4. El-Shazly AM, Awad SE, Hegazy MA, Mohammad KA, Morsy TA. Echinococcus granulosus/hydatidosis is an endemic zoonotic disease in Egypt. J Egypt Soc Parasitol 2007; 37: 609-622.

5. Ghanam ME, Shataat MA, Monib Mel-S, Hassan AA, Younis AI. Evaluation of the role of some parasitic infections as a cause of acute and chronic hepatic diseases. J Egypt Soc Parasitol 2001; 31(1): 37-42.

6. Mohey AH, Raafat MS, Fathia AMK. Seroepidemiological value of some hydatid cyst antigen in diagnosis of human cystic echinococcosis. J Parasit Dis 2016; 40(1): 52-56.

7. Eckert J, Conraths, FJ, Tackmann K. Echinococcosis: an emerging or re-emerging zoonosis? Int J Parasitol 2000; 30(12-13): 1283-1294.

8. Gottstein B, Reichen J. Echinococcosis/ Hydatidosis. In: Manson's Tropical Diseases, 22nd edition. Cook GC and Zumla AI (eds). Saunders Elsevier science limited, London. 2009, 1549-1568.

9. Gottstein B. Vaccination against echinococcosis? Ther Umsch 2005; 62(10): 685-693.

10. Sersar SI, Elnahas HA, Saleh AB, Moussa SA, Ghafar WA. Pulmonary parasitosis: Applied clinical and therapeutic issues. Heart Lung Circ. 2006; 15(1): 24 29.

11. Mandal S, Mandal DM. Human cystic echinococcosis: epidemiologic, zoonotic, clinical, diagnostic and therapeutic aspects. Asian Pac J Trop Med 2012; 253260.

12. Wani MM, Durrani AM, Shafi M, Wani M, Khan M. Hydatid disease of the soft tissues of the lower limb: case report. JK-Practitioner 2007; 4: 104-106.

13. Azab ME, Bishara SA, Helmy H, Oteifa NM, El-Hosein LM, Ramzy RM et al. Molecular characterization of Egyptian human and animal E. granulosus isolates by RAPD-PCR technique. J Egypt Soc Parasitol 2004; 34(1): 83-96.
14. Magambo J, Njoroge E, Zeyhle E. Epidemiology and control of echinococcosis in sub-Saharan Africa. Parasitol Int 2006; 55: 193-195.

15. Shahnazi M, Hejazi H, Salehi M, Reza Andalib AA. Molecular characterization of human and animal Echinococcus granulosus isolates in Isfahan, Iran. Acta Trop 2011; 117: 47-50.

16. Abdel Aaty HE, Abdel-Hameed DM, Alam-Eldin YH, El-Shennawy SF, Aminou HA, Makled SS et al. Molecular genotyping of Echinococcus granulosus in animal and human isolates from Egypt. Act Trop 2012; 121: 125-128

17. Khalifa NO, Khater HF, Nassief MZ. Genetic fingerprint of unilocular hydatidosis in Egyptian camels and humans using nested PCR. Pak Vet J 2014; 34(4): 522-526.

18. Carmena D, Benito A, Eraso E. Antigens for the immunodiagnosis of Echinococcus granulosus infection: An update. Acta Trop 2006; 98: 74-86.

19. Khabiri AR, Bagheri F, Assmar M, Siavashi MR Analysis of specific IgE and IgG subclass antibodies for diagnosis of Echinococcus granulosus. Parasite Immunol 2006; 28(8): 357-362.

20. Daeki AO, Craig PS, Shambesh MK. IgG-subclass antibody responses and the natural history of hepatic cystic echinococcosis in asymptomatic patients. Ann Trop Med Parasit 2000; 94(4): 319-328.

21. Garcia LS, Tissue Cestodes: Larval Forms In: Garcia LS (editor) Diagnostic Medical Parasitology ASM press Washington DC 2007: 386-412.

22. Zhang W, Li JH, Lin R, McManus DP. Immunology and immunodiagnosis of cystic echinococcosis: An Update. Clin Dev Immunol 2012; 1-10.

23. Zhang LH, Eslami A, Hosseini SH, McManus DP. Indication of the presence of two distinct strains of Echinococcus granulosus in Iran by mitochondrial DNA markers. Am J Trop Med Hyg 1998; 59(1): 171174.

24. Nasrieh MA, Abdel-Hafez SK. Echinococcus granulosus in Jordan: Assessment of various antigenic preparations for use in the serodiagnosis of surgically confirmed cases using enzyme immunoassays and the indirect hemagglutination test. Diagn Microbiol Infect Dis 2003; 48: 117-123.

25. Bradford MM. A rapid and sensitive method for the quantitation of microgram quantities of protein 
utilizing the principle of protein - dye binding. Anal Biochem 1976; 72: 248-254.

26. Laemmli UK. Cleavage of structural proteins during the assembly of the head of bacteriophage T4. Nature 1970; 227: 680-685.

27. Shariff GM, Parija SC. Co-agglutination (Co-A) test for circulating antigen in hydatid disease. $\mathrm{J}$ Med Microbiol 1993; 38: 231-234.

28. Towbin H, Staehelin T, Gordon. Electrophoretic transfer of proteins from polyacrylamide gels to nitrocellulose sheets: Procedure and some applications. Proc Nat Acad Sci USA, 1979, 76: 4350-4354.

29. Timmons TM, Dunbar DS. One-dimensional gel electrophoresis. In: Guide to Protein Purification, edited by Deutscher, M. P., Academic Press Inc.; SanDiego, California, USA, section XI, 1990, 52: 679-687.

30. Wachira TM, Bowles J, Zeyhle E, McManus DP. Molecular examination of the sympatry and distribution of sheep and camel strains of Echinococcus granulosus in Kenya. Am J Trop Med Hyg 1993; 48: 473-479.

31. Bart JM, Abdukader M, Zhang YL, Lin RY, Wang YH, Nakao $\mathrm{M}$ et al. Genotyping of human cystic echinococcosis in Xinjiang, PR China. Parasitology 2006; 133(5): 571-579.

32. Alam-Eldin YH, Abdel Aaty HE, Ahmed MA. Molecular characterization of cystic echinococcosis: First record of G7 in Egypt and G1 in Yemen. Acta Parasitol 2015; 60(4): 662-665.

33. Ahmed ME, Aradaib IE. Surgical management of a case of multiple hydatidosis. Surg J 2006; (1): 17-19.

34. Al-Sherbiny MM, Farrag MKA, Fayad MH, Makled MK, Tawfeek GM, Ali NMS. Application and assessment of a dipstick assay in the diagnosis of hydatidosis and trichinosis. Parasitol Res 2004; 93: 87-95.
35. Chaya DR, Parija SC. Evaluation of a newly designed sandwich enzyme linked immunosorbent assay for the detection of hydatid antigen in serum, urine and cyst fluid for diagnosis of cystic echinococcosis. Trop Parasitol 2013; 3(2): 125-131.

36. Sadaka HA, Khalifa AM, Eldein SZ, Taha K, Eldein KM. Urinary antigen detection for diagnosis of hydatid disease. J Egypt Soc Parasitol 2002; 32(1): 69-78.

37. Devi CS, Parija SC. A new serum hydatid antigen detection test for diagnosis of cystic echinococcosis. Am J Trop Med Hyg 2003; 69(5): 525-528.

38. Zhang W, Li J, McManus DP. Concepts in immunology and diagnosis of hydatid disease. Clin Microbiol Rev 2003; 16: 18-36

39. Reiterová K, Auer H, Altintaś N, Yolasigmaz A. Evaluation of purified antigen fraction in the immunodiagnosis of cystic echinococcosis. Parasitol Res 2014; 113: 2861-2867.

40. Mariconti M, Bazzocchi C, Tamarozzi F, Meron $\mathrm{V}$, Genco F, Maserati R et al. Immunoblotting with human native antigen shows stage-related sensitivity in the serodiagnosis of hepatic cystic echinococcosis. Am J Trop Med Hyg 2014; 90(1): 75-79.

41. Haniloo A, Massoud J, Rokni MB. Evaluation and comparison of antigen B-ELISA and antigen B-immunoblotting in immunodiagnosis of cystic hydatid disease. Pak J Med Sci 2005; 21(3): 352-356.

42. Di Felice G, Pini C, Afferni C, Vicari G. Purification and partial characterization of the major antigen of Echinococcus granulosus (antigen 5) with monoclonal antibodies. Mol Biochem Parasitol 1986; 20: 133-142.

43. Lightowlers MW, Liu D, Haralambous A, Rickard MD. Subunit composition and specificity of the major cyst fluid antigens of Echinococcus granulosus. Mol Biochem Parasitol 1989; 37: 171-182. 